\title{
Article \\ Copper-Tantalum Metal Matrix Composites Consolidated from Powder Blends by Severe Plastic Deformation
}

\author{
Zachary S. Levin ${ }^{1,2, *}$, Michael J. Demkowicz ${ }^{2}$ and Karl T. Hartwig ${ }^{2,3}$ \\ 1 MST-16, Los Alamos National Laboratory, Los Alamos, NM 87545, USA \\ 2 Department of Materials Science and Engineering, Texas A\&M University, College Station, TX 77840, USA; \\ demkowicz@tamu.edu (M.J.D.); thartwig@tamu.edu (K.T.H.) \\ 3 Shear Form, Inc., Bryan, TX 77801, USA \\ * Correspondence: zlevin@lanl.gov
}

Citation: Levin, Z.S.; Demkowicz, M.J.; Hartwig, K.T. Copper-Tantalum Metal Matrix Composites

Consolidated from Powder Blends by Severe Plastic Deformation. Metals 2021, 11, 1010. https://doi.org/ $10.3390 /$ met11071010

Academic Editors: Tilmann Beck and Andreas Chrysanthou

Received: 27 April 2021

Accepted: 17 June 2021

Published: 24 June 2021

Publisher's Note: MDPI stays neutral with regard to jurisdictional claims in published maps and institutional affiliations.

Copyright: (c) 2021 by the authors. Licensee MDPI, Basel, Switzerland. This article is an open access article distributed under the terms and conditions of the Creative Commons Attribution (CC BY) license (https:// creativecommons.org/licenses/by/ $4.0 /)$.

\begin{abstract}
We investigated the effectiveness of severe plastic deformation by equal channel angular extrusion (ECAE) for consolidation of metal powders into metal matrix composites. Equal volumes of copper $(\mathrm{Cu})$ and tantalum (Ta) powders were consolidated at ambient temperature via different ECAE routes. Composites processed by ECAE routes $4 \mathrm{E}$ and $4 \mathrm{Bc}$ were also processed at $300^{\circ} \mathrm{C}$. The resulting materials were characterized by scanning electron microscopy (SEM) and compression testing. Processing by route $4 \mathrm{Bc}$ at $300{ }^{\circ} \mathrm{C}$ resulted in the highest compressive strength, lowest anisotropy, and least strain rate sensitivity. We conclude that the superior properties achieved by this route arise from mechanical bonding due to interlocking $\mathrm{Cu}$ and Ta phases as well as enhanced metallurgical bonds from contact of pristine metal surfaces when the material is sheared along orthogonal planes.
\end{abstract}

Keywords: metal matrix composite MMC; equal channel angular extrusion ECAE; copper-tantalum; powder consolidation; severe plastic deformation

\section{Introduction \\ 1.1. Metal Matrix Composites}

Our goal is to examine the prospects for using equal channel angular extrusion (ECAE) to consolidate powders at low temperature (i.e., without sintering) into metal matrix composites (MMCs) with controlled microstructure. MMCs, also referred to as pseudo-alloys, are a class of materials that have a composite structure with a metal matrix. The matrix phase can either be an alloy [1] or single element [2], while the filler phase can be metal [3,4], intermetallic [5,6], or ceramic [7,8]. Like all composites, MMCs have the potential for unique combinations of properties that can exceed those of their constituent components. Multiple variables influence the properties of MMCs, including composition [9,10], microstructure [11], and processing history [12-18]. For example, tungsten heavy alloys combine the high density, strength, and thermal stability of tungsten while enhancing ductility through the incorporation of an iron or nickel alloy matrix $[19,20]$.

MMC fabrication usually involves powder consolidation and may be broadly divided into liquid or solid-state processing [21]. Liquid processing includes dispersion of fillers in a liquid matrix phase, infiltration of fiber networks with molten metal, or thermal spray processing. This approach can be used to produce large parts with methods similar to traditional casting and forming. However, it is limited to low melting temperature alloys. Moreover, maintaining uniform composition can be challenging. Finally, constituent reactions, grain coarsening, and oxidation can degrade mechanical properties [22].

Solid state processing, including powder metallurgy (PM) methods, can also be used to produce MMC [23]. This approach can impart greater property uniformity due to better control over powder mixtures prior to fabrication. This approach may be used on materials with very high melting points. Nevertheless, while sintering temperatures are lower than 
melting, the metal phases still coarsen, limiting grain size strengthening, and phase changes may occur as temperatures vary during processing.

The other solid-state fabrication techniques for MMCs rely on diffusion bonding produced by intimate contact between metal surfaces subjected to severe plastic deformation (SPD) combined sometimes with elevated temperature during processing or after SPD. Techniques that use this approach include wire drawing and restacking [24], accumulative roll bonding (ARB) [25,26], and ECAE [27-30]. Through intensive shear, these processes are able to consolidate and bond metal constituents and are effective at minimizing porosity, sometimes reaching near theoretical density. Of these techniques, ECAE is the only one that can produce a nearly isotropic distribution of the matrix and filler phases. ECAE can also produce bulk material that can either be worked further or directly machined into parts. At the same time, ECAE enables greater control over microstructure, texture, and morphology than pressing and sintering alone.

$\mathrm{Cu}$ and Ta have near complete immiscibility below $1084{ }^{\circ} \mathrm{C}$ and do not form any intermetallic compounds [31,32]. Cu is face centered-cubic (FCC) while Ta is body centered-cubic (BCC). Other researchers have investigated the fabrication of $\mathrm{Cu}$-Ta alloys by ECAE $[33,34]$. In these earlier investigations, the $\mathrm{Cu}$ and Ta powders we pre-mixed and mechanically ball milled prior to consolidation by ECAE, resulting in a nearly pure FCC Cu with dispersed BCC Ta nanoclusters [35]. The Ta nanoclusters significantly improved the mechanical behavior and thermal stability without significantly impacting other properties like conductivity [36]. The retention of distinct FCC Cu and BCC Ta phases in these systems after severe deformation processing, first during milling then by ECAE, provides the opportunity to examine mechanical response in this multi-phase system composed of distinct, unalloyed metal phases.

While these previous works have focused on Ta nanocluster-reinforced $\mathrm{Cu}$, in the current work we have investigated the consolidation of blended $\mathrm{Cu}$ and Ta powders of equal volume. Our motivation is to develop a new material that will be used for further computation and modeling studies involving the impact of phase interface conditions, phase crystal structure differences, and density differences on quasi-static and intermediate strain rate mechanical behavior. Our investigation proceeded in two steps. First, a number of routes were selected for processing at ambient temperature in order to examine the impact of total strain and deformation path on morphology and the effectiveness of consolidation. In the second stage, a candidate was selected for further processing at elevated temperature. The effectiveness of consolidation was evaluated through compression testing and the microstructure characterized by electron microscopy.

\section{2. $E C A E$}

The ECAE process involves extruding a billet-typically with square or circular cross section-through a confined channel with a sharp change in direction between the inlet and exit. Common angles for this direction shift are $90^{\circ}$ and $120^{\circ}$, however any angle between $90^{\circ}$ and $180^{\circ}$ may be used. As the work piece is forced through the intersecting channels, the material undergoes simple shear, imparting a significant amount of strain. For a $90^{\circ}$-intersecting angle, the resulting shear strain is approximately 1.16 , which is roughly equivalent to a $69 \%$ area reduction in conventional extrusion. A detailed review on ECAE may be found in Segal's work [37,38].

Unlike rolling, drawing, or swaging, ECAE may be used to produce a variety of microstructure morphologies and textures by varying the ECAE processing route, i.e., the types and sequence of billet rotations between extrusions. The microstructures that can be produced fall into three categories: lamellar, filamentary, and equiaxed. Repeated extrusions without billet rotation continuously elongate the microstructures along one plane producing lamellar structures [39]. Rotation of the billet by alternating $+90^{\circ}$ and $-90^{\circ}$ rotations between extrusion passes deforms the microstructure along both the longitudinal and flow planes, elongating structures on two axes producing a fibrous structure, and is referred to as route B [16]. 
Finally, by rotating the billet so that an initial volume element is restored produces an equiaxed microstructure. Three different routes yield this outcome: $\mathrm{C}, \mathrm{E}$, and Bc. Route $\mathrm{C}$ is the simplest of these and is accomplished by rotating the billet $180^{\circ}$ between extrusions. Route $\mathrm{E}$ builds on route $\mathrm{C}$, by combining two route $\mathrm{C}$ extrusions with a $90^{\circ}$ rotation between them. For route $\mathrm{Bc}$, the billet is rotated $+90^{\circ}$ between each extrusion, and after 4 extrusions the volume element is restored. For this reason, it is uncommon to see routes with the Bc suffix without a multiple of 4 in front of them, e.g., $4 \mathrm{Bc}$ or 8Bc. The ability to control microstructure combined with the large strain space accessible and bulk workpiece dimensions make ECAE an ideal tool for studying the impact of microstructure morphology on the mechanical behavior of MMCs.

\section{Materials and Methods}

We have examined the impact of processing route, total strain, and processing temperature on the mechanical behavior of copper $(\mathrm{Cu})$-tantalum $(\mathrm{Ta})$ blended powder composites. $\mathrm{Cu}$ and Ta do not form compounds and have minimal solubility over their entire composition up to the solidus. Their differing crystal structures ( $\mathrm{Cu}$ is FCC while Ta is BCC) and densities $\left(8.96 \mathrm{~g} / \mathrm{cm}^{3}\right.$ for $\mathrm{Cu}$ and $16.65 \mathrm{~g} / \mathrm{cm}^{3}$ for Ta) make them interesting model materials for high strain rate mechanical testing, in particular to study the influence of heterophase interfaces and large elastic impedance mismatch.

The consolidation process is optimized by initially conducting extrusions at ambient temperatures following a variety of routes followed by characterization of the microstructure and mechanical behavior of the consolidated material. Promising routes were selected for processing at $300{ }^{\circ} \mathrm{C}$. Materials consolidated at these elevated temperatures were then mechanically tested in multiple orientations and at different strain rates in order to determine the effectiveness of the processing.

The $\mathrm{Cu}$ and Ta powders used in this investigation are pictured in Figure 1. Their size and aspect ratio were found by analyzing scanning electron microscopy (SEM) images with the Fiji ImageJ software [40].
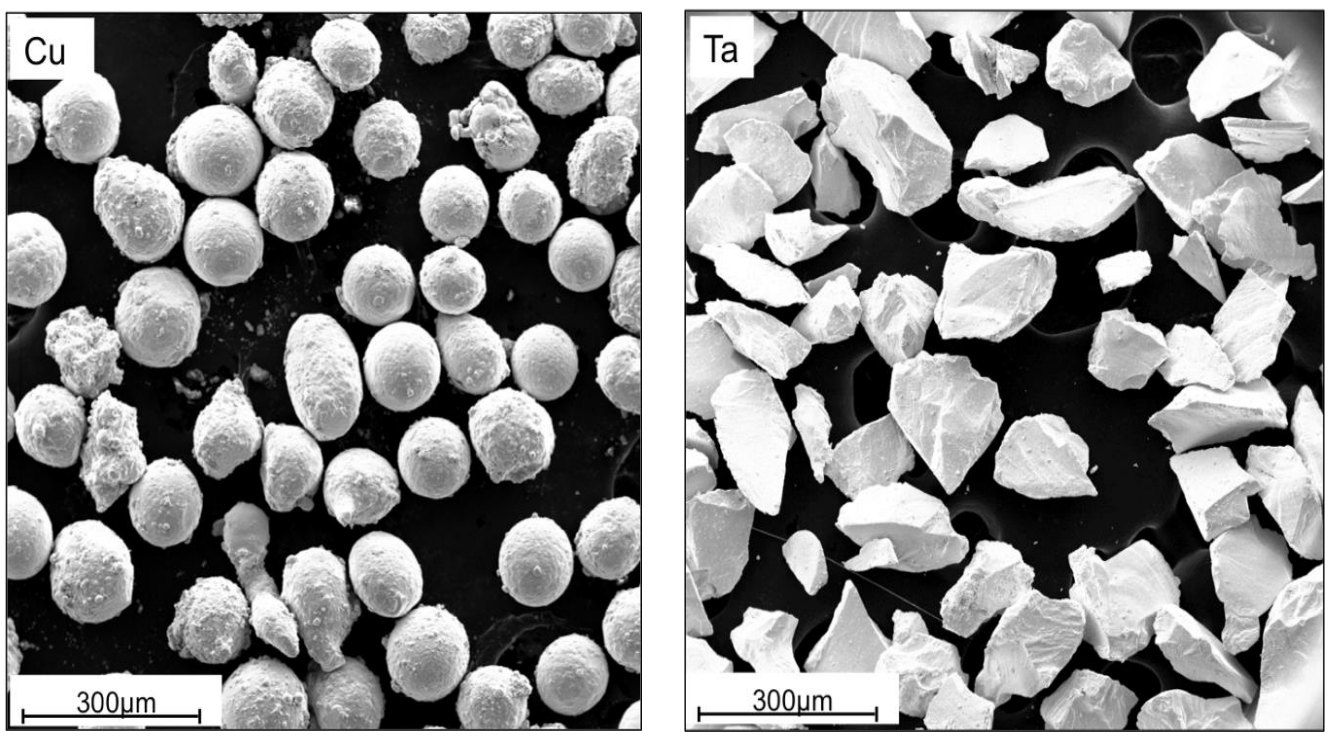

Figure 1. SEM micrographs of initial $\mathrm{Cu}$ (left) and Ta (right) powders used in consolidation.

The $\mathrm{Cu}$ powder was sourced from Alfa Aesar (Haverhill, MA, USA). It is spherical with an average diameter of $126 \mu \mathrm{m} \pm 15 \mu \mathrm{m}$ and an aspect ratio of $1.2 \pm 0.2$. Ta powder was provided by H.C. Stark (Goslar, DEU) and is HRC grade capacitor powder. The particles possess an average diameter of $153 \mu \mathrm{m} \pm 47 \mu \mathrm{m}$ and aspect ratio of $1.8 \pm 0.6$. Cans used for extrusion were made of 304 stainless steel. Each can was approximately $178 \mathrm{~mm}$ long, with a cross section of $25 \mathrm{~mm} \times 25 \mathrm{~mm}$ and included a circular center cavity 
$140 \mathrm{~mm}$ long with diameter $12.5 \mathrm{~mm}$. Plugs for the cans where $38 \mathrm{~mm}$ long and $12.5 \mathrm{~mm}$ in diameter and also made of 304 stainless steel. Powder handling was done in a glove box under an argon atmosphere.

Powders were combined in a 1:1 ratio by volume, equivalent to a mass ratio of 1:1.86. The powder mixture was then sealed inside a plastic wide-mouth Nalgene bottle. The Nalgene bottle was removed from the glove box and agitated inside a Turbula T2F Powder Mixer Shaker (WAB US Corp., Allendale, NJ, USA) for $20 \mathrm{~min}$. Mixed powders were added to the cans inside the glove box and a metal plug inserted and sealed with black electrical tape. Prior to extrusion, cans were pre-compacted and sealed with a manually operated hydraulic press in order to minimize oxidation. Graphite sheet was wrapped around the cans to reduce friction during ECAE.

The cans were extruded using a $25.4 \mathrm{~mm}^{2}$ square cross section, sliding wall, zero degree fan angle ECAE tool at approximately $10 \mathrm{~mm} / \mathrm{s}$. For processing at elevated temperatures, the ECAE tool was pre-heated to the desired temperature. Billets were placed into the tool pre-upset to ensure good contact with the channel walls and to maintain the seal between the plug and can wall. They were allowed to reach thermal equilibrium with the tool for $30 \mathrm{~min}$ before extrusion.

Mechanical properties were obtained through uniaxial compression testing at a quasistatic strain rate of $10^{-3} / \mathrm{s}$. Samples were prepared by sectioning with a silicon carbide cutting saw and mechanically polished down to 800-grit using silicon carbide polishing pads. The samples processed at ambient temperature measured $3 \times 3 \times 6 \mathrm{~mm}^{3}$ while those processed at elevated temperature measured $4 \times 4 \times 8 \mathrm{~mm}^{3}$. The length-to-width ratios of these samples are small enough to ensure that buckling is not a concern for these compression tests. The load frame used during testing has high compliance. Therefore, our stress-strain curves do not permit the reliable determination of elastic moduli.

During testing, samples were placed between tungsten carbide platens affixed to the load frame. Graphite sheet was used as a lubricant between the sample and the platens. Strain was measured at the tungsten carbide platens by an MTS model 632.53E-14 extensometer (MTS, Eden Prairie, MN, USA) with a gauge length of $12.7 \mathrm{~mm}$. The platen/graphite sheet/sample/graphite sheet/platen stack nevertheless appears to have significant compliance (as evidenced in the different loading/unloading moduli shown in Supplementary Table S1), so we do not believe our stress-strain curves permit reliable determination of elastic moduli. Material processed at elevated temperature was tested along the three primary extrusion orientations: longitudinal, extrusion, and flow directions. Two additional strain rates- $10^{-2} / \mathrm{s}$ and $10^{-1} / \mathrm{s}$-were investigated for the high temperature material along the extrusion direction. Material quantity limitations permitted a limited number of these additional tests. Compression testing was halted when either the load frame reached its safe limit, the load on the samples dropped, or deflection of the sample reached a critical state which might harm the test frame or extensometer.

Material microstructure was characterized using optical microscopy and SEM. Samples were hand polished with silicon carbide pads to 800 grit followed by polishing on a felt pad with colloidal silica and finished on a vibratory polisher with colloidal silica.

\section{Results}

\subsection{Room Temperature Processing}

\subsubsection{Microstructure}

The scanning electron micrographs in Figure 2 show materials processed by routes $1 \mathrm{~A}, 2 \mathrm{~A}, 2 \mathrm{~A} \times 2 \mathrm{~A}, 2 \mathrm{C}$ and $4 \mathrm{E}$ at ambient temperature. Ta is the brighter phase. Images are taken along the flow plane of extrusion; the arrow indicates the extrusion direction. Visual inspection suggests that the constituents are well-consolidated, with intimate contact between the $\mathrm{Cu}$ and Ta phases and no apparent porosity. Route 1A (top left) produced an elongated microstructure, as anticipated. A small pore can be seen in the copper phase at the interface of the Ta phase which is indicated by an arrow. In the 2A material (top 
middle), the substantial increase in elongation over the $1 \mathrm{~A}$ is clearly evident. This outcome is to be expected, as the degree of elongation compounds with each route A type extrusion.
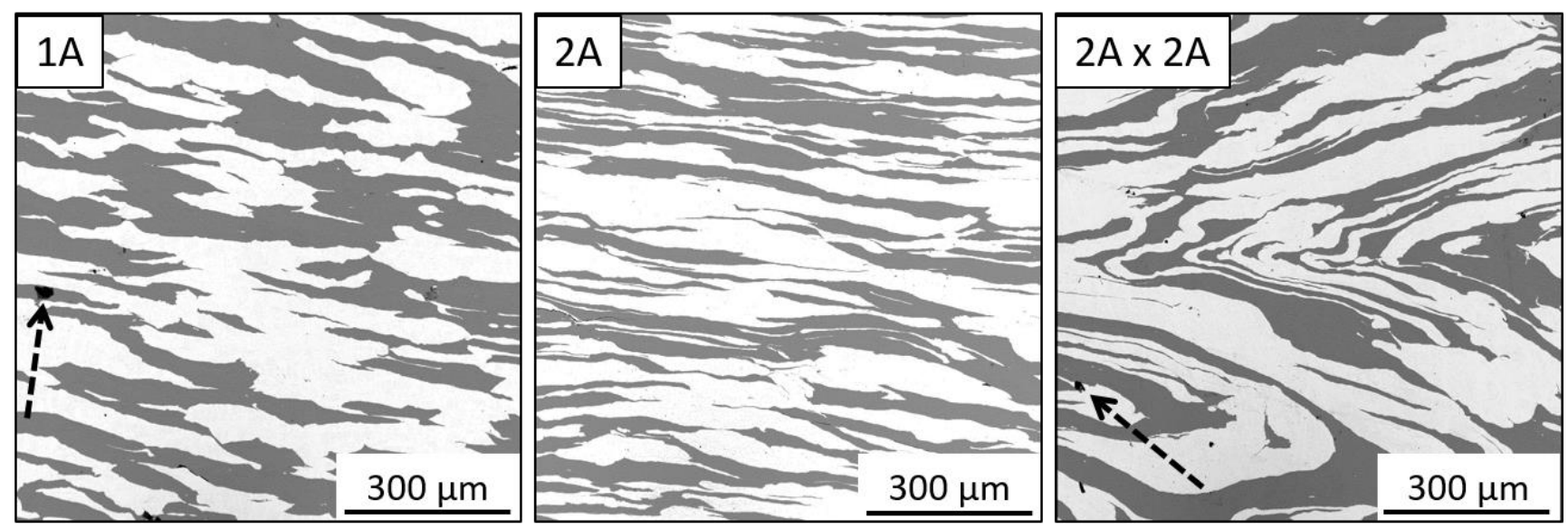

Flow Plane
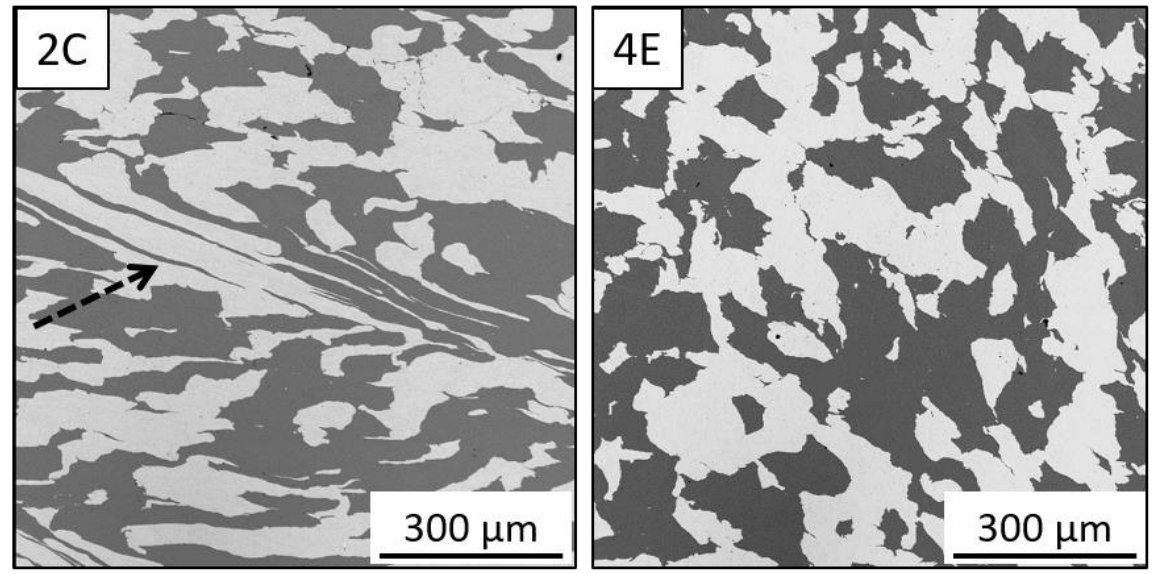

Figure 2. Micrographs on the Flow plane of $\mathrm{Cu}$-Ta composites consolidated at ambient temperature by ECAE routes $1 \mathrm{~A}, 2 \mathrm{~A}$, $2 \mathrm{~A} \times 2 \mathrm{~A}, 2 \mathrm{C}$, and $4 \mathrm{E}$.

Route $2 \mathrm{~A} \times 2 \mathrm{~A}$ is an experimental extrusion route where, after two route $\mathrm{A}$ extrusions, the billet was rotated $180^{\circ}$ and extruded two more times by route $\mathrm{A}$, thereby returning the deformed volume element to its original shape. This was done with the intent of producing the maximum amount of diffusion bonding between the $\mathrm{Cu}$ and Ta phases by maximizing their contact area while still arriving at an equiaxed microstructure at the end of processing. However, the intended effect was not achieved. As can be seen from the micrograph labeled $2 \mathrm{~A} \times 2 \mathrm{~A}$ (top right), the material components folded, instead of returning to their original shapes. This folding may have begun by shear localization or kinking of the layered morphology in 2A. A pore is noted by an arrow in this material.

Deformation caused by shear localization may be seen in the micrograph of the sample processed by route $2 \mathrm{C}$ (bottom left), and indicated by arrows, where the Ta layer has been drawn out at an angle from the extrusion direction. Route $4 \mathrm{E}$ (bottom right), which involves a $2 \mathrm{C}$ extrusion followed by a $90^{\circ}$ rotation and then another $2 \mathrm{C}$ extrusion, has the most equiaxed structure. The same type of shear localization that occurred in the $2 \mathrm{C}$ sample is not observed in the $4 \mathrm{E}$ material. This is unexpected as both entail the same $2 \mathrm{C}$ processing steps. However, as Figure 2 only shows a limited sample area, we cannot exclude the possibility of folded phase morphologies in other parts of the $4 \mathrm{E}$ sample.

A summary of the results obtained from the ambient temperature extruded samples is shown in Table 1, which includes the accumulated strain, the Vickers hardness measured with a $300 \mathrm{~g}$ load, the area fraction of the $\mathrm{Cu}$ phase, and the $\mathrm{Cu}$-Ta interface trace length per unit area of the section. The values following the plus/minus $( \pm)$ sign are the standard 
deviations of the measured value. Vickers hardness values increase with the amount of strain, consistent with an increase in dislocation density and refinement of grains. These processes typically occur in cold worked material and have been observed in both pure $\mathrm{Cu}$ [41] and Ta [29] processed by ECAE.

Table 1. Summary of total accumulated strain, Vickers hardness, $\%$ area of $\mathrm{Cu}$ phase, and phase boundary trace length per unit area for each ECAE processing route.

\begin{tabular}{ccccc}
\hline Route & Strain & Hardness HV300 & \% Cu Area & $\begin{array}{c}\text { Interface Trace Length per Unit Area } \\
{\left[\boldsymbol{\mu m}^{-1} \text { ] }\right.}\end{array}$ \\
\hline $1 \mathrm{~A} \mathrm{Cu}-\mathrm{Ta}$ & 1.15 & $164 \pm 12$ & $46 \pm 5$ & $4 \pm 0.3$ \\
$2 \mathrm{~A} \mathrm{Cu}-\mathrm{Ta}$ & 2.3 & $177 \pm 12$ & $42 \pm 5$ & $6 \pm 0.7$ \\
$2 \mathrm{~A} \times 2 \mathrm{~A} \mathrm{Cu}-\mathrm{Ta}$ & 4.6 & $190 \pm 18$ & $47 \pm 6$ & $3.6 \pm 0.7$ \\
$2 \mathrm{C} \mathrm{Cu}-\mathrm{Ta}$ & 2.3 & $174 \pm 23$ & $42 \pm 4$ & $4.6 \pm 0.7$ \\
$4 \mathrm{E} \mathrm{Cu}-\mathrm{Ta}$ & 4.6 & $188 \pm 25$ & $53 \pm 4$ & $3.1 \pm 0.6$ \\
\hline
\end{tabular}

The area fraction of $\mathrm{Cu}$ area nominally ought to be $50 \%$ in all samples, since all were prepared from $50 \% \mathrm{Cu}$ powder, by volume. Deviations from this expected value may be attributed to a several possible sources. Powders may have segregated somewhat while samples were prepared, transferred, or extruded creating a non-uniform distribution of the $\mathrm{Cu}$ and Ta. ECAE processing may have induced an anisotropic phase distribution, resulting in an observed area fraction that depends on sectioning plane. This conclusion is consistent with the $4 \mathrm{E}$ sample, which has the most equiaxed microstructure but a $\mathrm{Cu}$ area greater than $50 \%$. The interface trace length per unit area was determined using the ImageJ software. The substantial differences in this quantity from sample to sample are due to the differing aspect ratios of the constituent phases.

\subsubsection{Mechanical Behavior}

The mechanical response of the room temperature processed composites was evaluated by quasi-static $\left(10^{-3} / \mathrm{s}\right)$ compression testing. Characteristic experimental stress-strain curves for each test condition are shown in Figure 3. The curves presented are representative of the individual cases and were selected to illustrate the differences in mechanical behavior of each processing condition. Two sets of compression tests were conducted; the first was under monotonic loading, displayed in Figure 3, and the second with periodic unloads. For most samples, $1 \mathrm{~A}, 2 \mathrm{~A}, 2 \mathrm{~A} \times 2 \mathrm{~A}$ and $2 \mathrm{C}$, a pronounced load drop occurred before unloading could be applied, or shortly thereafter.

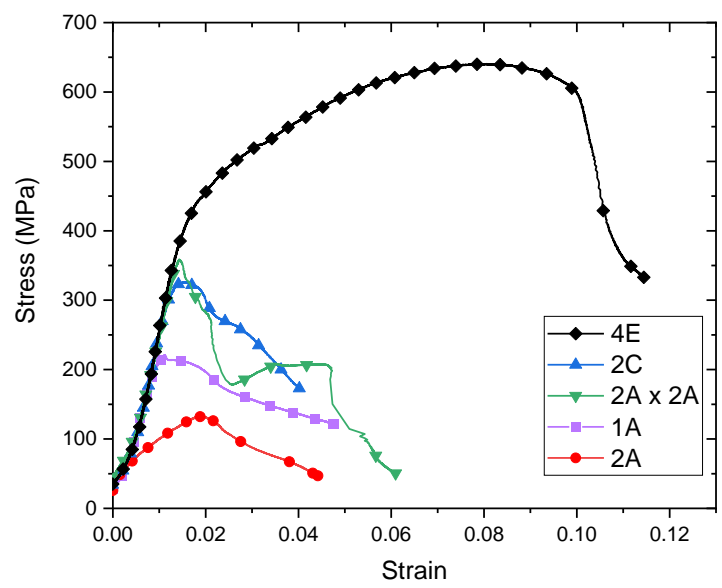

Figure 3. Experimental compression stress-strain curves for $\mathrm{Cu}$-Ta composites consolidated at ambient temperature.

Most of the samples exhibited a sharp decline in load near the elastic limit. During testing, samples did not barrel but instead tended to shear, resulting in a lateral deflection 
of the top and bottom surfaces of the compression sample, which in turn put lateral stress on the load frame. When this occurred, testing was halted in order to minimize any risk of damaging the load frame. Samples did not fracture in these tests. Rather, they appeared to shear, sometimes fissures appeared, but the samples always remained intact such that no fracture surfaces were available for inspection. The material processed by route $4 \mathrm{E}$ deformed well beyond the elastic limit and work-hardened prior to exhibiting a load drop. We conclude that this processing route was the most successful at producing a well-bonded composite. All associated stress-strain curves pertaining to this work are included in the Supplementary Information.

The $2 \mathrm{~A} \times 2 \mathrm{~A}$ and $2 \mathrm{C}$ materials have similar strains and stresses beyond the elastic limit. This finding is unexpected as the $2 \mathrm{~A} \times 2 \mathrm{~A}$ material has twice the working of the $2 \mathrm{C}$ material. Moreover, while both of these materials were initially expected to have similar phase morphology, Figure 2 shows that they do not. Their comparable behavior may be the outcome of similar pre-existing flaw distributions. Processing by route $2 \mathrm{~A}$ appears to be the least successful at consolidation, as evidenced by this material's early deviation from elastic behavior and low ultimate stress and strain.

\section{2. $300{ }^{\circ} \mathrm{C}$ Processing}

\subsubsection{Microstructure}

Based on the initial stress-strain data, route $4 \mathrm{E}$ was selected for further investigation in elevated temperature $\left(300^{\circ} \mathrm{C}\right)$ consolidation. We also conducted elevated temperature processing by route $4 \mathrm{Bc}$ as it gives rise to similar volume element deformation as route $4 \mathrm{E}$ : both routes produce an equiaxed final microstructure as the initial volume element is restored. The difference between these routes is related to the order of billet rotation between extrusion passes. In route $4 \mathrm{E}$ the volume element is returned to its initial condition in the second and fourth passes with a $90^{\circ}$ rotation between the second and third, while in route $4 \mathrm{Bc}$ the volume element is only restored upon the fourth extrusion. Thus, route $4 \mathrm{Bc}$ is expected to impose greater elongation of the particles between the first and second extrusions, increasing the amount of particle-particle bonding.

Composite images of microstructures along the flow, longitudinal, and extrusion planes for both processing routes are shown in Figure 4. Cu is the darker phase. Table 2 summarizes the $\mathrm{Cu}$ area fraction as well as the interface trace length per unit area for both samples. The marked differences in $\mathrm{Cu}$ area fraction on the different sectioning planes suggest that the anisotropy of the composite structure is the likely cause of variations in these quantities reported in Table 1 for the samples processed at ambient temperature. The difference in interface trace length for $4 \mathrm{Bc}$ indicates a greater $\mathrm{Cu}$-Ta interface area and improved bonding between phases.

Table 2. Summary of phase boundary trace length per unit area and \% area of $\mathrm{Cu}$ phase for $\mathrm{Cu}$-Ta composites processed at $300{ }^{\circ} \mathrm{C}$.

\begin{tabular}{|c|c|c|c|c|c|}
\hline \multirow{2}{*}{$\begin{array}{c}\text { Processing } \\
\text { Route }\end{array}$} & \multirow{2}{*}{$\begin{array}{c}\text { Oreintation } \\
\text { Plane }\end{array}$} & \multicolumn{2}{|c|}{$\%$ Interface Trace Length per Unit Area $\left[\mu \mathrm{m}^{-1}\right]$} & \multicolumn{2}{|c|}{$\%$ Cu Area } \\
\hline & & Individual & Average & Individual & Average \\
\hline- & Flow & 3.6 & - & 47 & - \\
\hline $4 \mathrm{E}$ & Longitudinal & 3.5 & $3.7 \pm 0.2$ & 39 & $46 \pm 7$ \\
\hline- & Extrusion & 3.9 & - & 53 & - \\
\hline- & Flow & 4.1 & - & 48 & - \\
\hline $4 \mathrm{Bc}$ & Longitudinal & 4.4 & $4.5 \pm 0.4$ & 41 & $43 \pm 4$ \\
\hline- & Extrusion & 4.9 & - & 41 & - \\
\hline
\end{tabular}



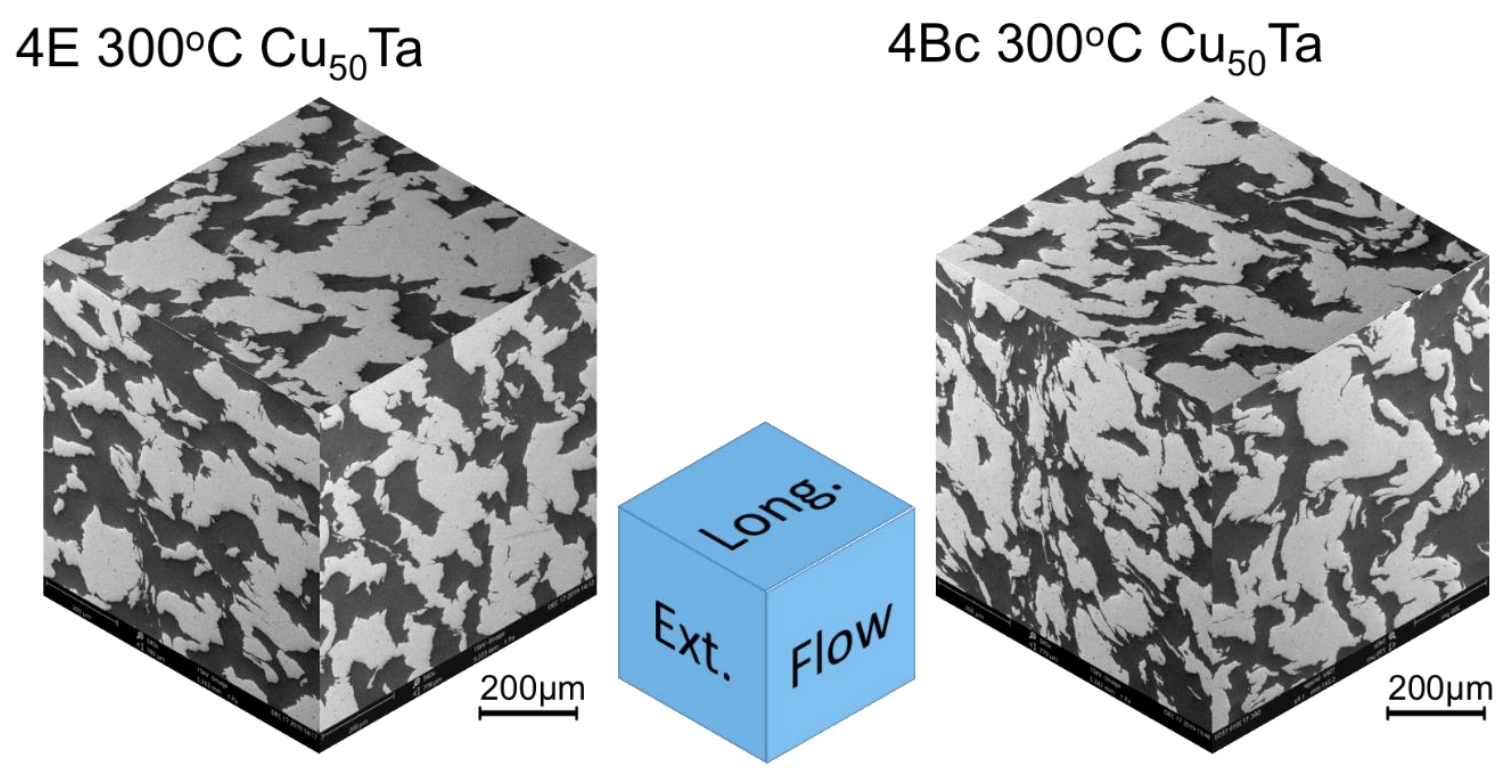

Figure 4. 3-D representation of microstructure along three different sectioning planes in $\mathrm{Cu}$-Ta composites consolidated at $300{ }^{\circ} \mathrm{C}$ by routes $4 \mathrm{E}$ and $4 \mathrm{Bc}$.

\subsubsection{Mechanical Behavior}

Compression stress-strain curves for route $4 \mathrm{E}$ and $4 \mathrm{Bc}$ materials processed at $300{ }^{\circ} \mathrm{C}$ are shown in Figure 5. For comparison, the stress-strain curve for route $4 \mathrm{E}$ consolidation at ambient temperature is also shown. Both $300^{\circ} \mathrm{C}$ materials exhibit comparable mechanical response. They are more ductile than the ambient temperature processed material, as neither exhibited a load drop in the test range. Their yield stresses are nearly the same. However, the $4 \mathrm{Bc}$ material appears to undergo more strain hardening than the $4 \mathrm{E}$ material. By contrast, the ambient temperature processed material is approximately $20 \%$ stronger than both samples processed at $300{ }^{\circ} \mathrm{C}$. This difference may be due to greater recovery of dislocation densities in the $\mathrm{Cu}$ phase of the composites processed at elevated temperature.

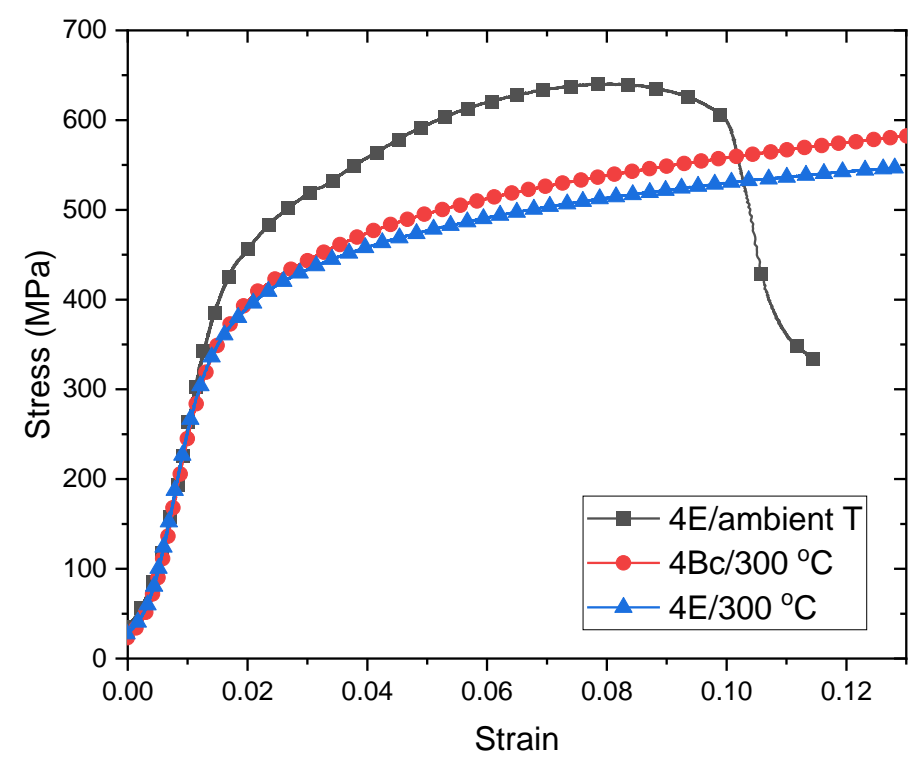

Figure 5. Compression stress-strain curves for $\mathrm{Cu}$-Ta composites consolidated at $300^{\circ} \mathrm{C}$. For comparison, the stress strain curve for route $4 \mathrm{E}$ consolidation at ambient temperature is also shown. 
Mechanical anisotropy in the $300{ }^{\circ} \mathrm{C}$-processed materials was investigated by conducting quasistatic $\left(10^{-3} / \mathrm{s}\right)$ compression tests in the three orthogonal ECAE directions: longitudinal (LD), extrusion (ED) and flow (FD), as shown in Figure 4. Stress-strain curves for the $4 \mathrm{E}$ and $4 \mathrm{Bc} 300{ }^{\circ} \mathrm{C}$ tests are shown in Figure $6 \mathrm{a}, \mathrm{b}$. Both materials are plastically isotropic, to a good approximation. The largest deviation in isotropy occurs for deformation of the route $4 \mathrm{E}$ material along the extrusion direction (ED). The greater anisotropy in 4Bc material may be due to the increase in phase interface area noted in Table 2. This greater interface area likely results in improved bonding, and a more homogenous mechanical response and may also increase strength.
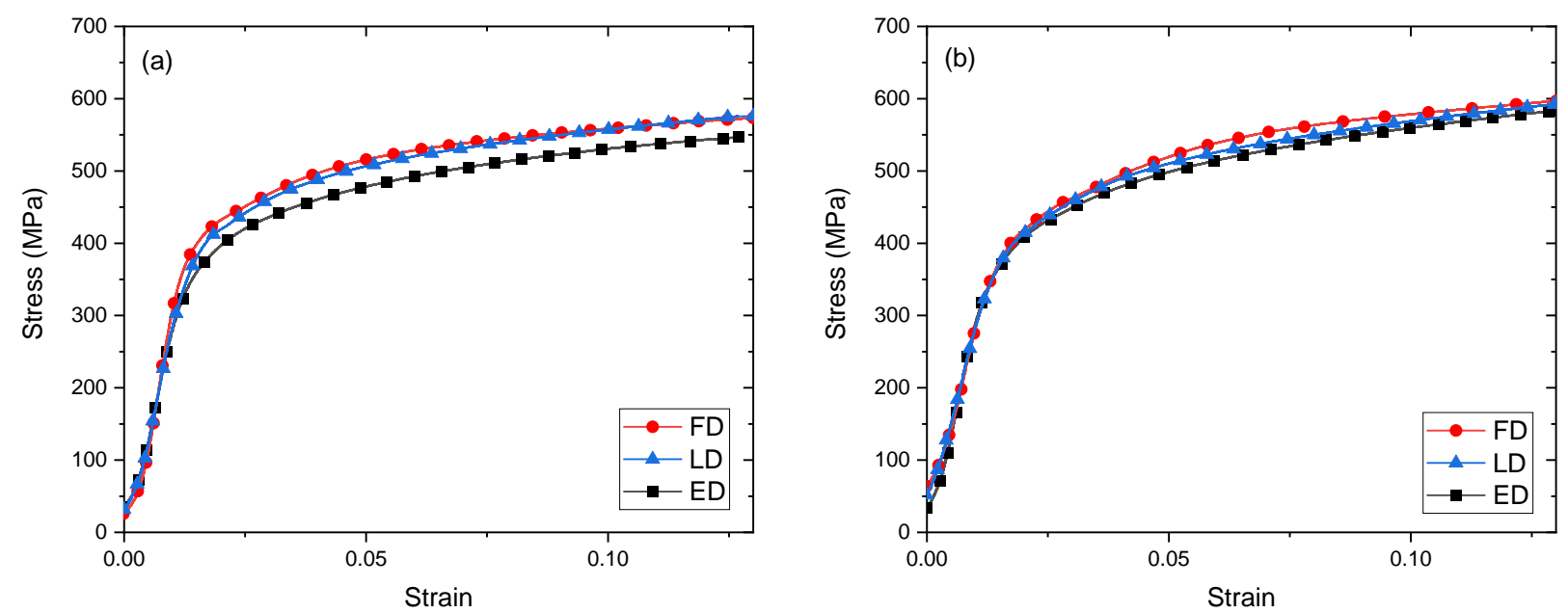

Figure 6. Compression stress-strain curves for $\mathrm{Cu}$-Ta composites consolidated at $300{ }^{\circ} \mathrm{C}$ for tests along the extrusion direction (ED), longitudinal direction (LD), and flow direction (FD), (a) by route 4E, and (b) by route $4 \mathrm{Bc}$.

To assess strain rate sensitivity, the $300{ }^{\circ} \mathrm{C}$-processed composites were further tested under two additional strain rates along the extrusion direction (ED): $10^{-2} / \mathrm{s}$ and $10^{-1} / \mathrm{s}$. Corresponding stress-strain curves are shown in Figure 7. A summary of the results for all testing directions and strain rates is shown in Table 3 . The strain rate sensitivity exponent $\mathrm{m}$ was calculated by determining the slope of the log-log plot of strain rate vs. stress at stains at $5 \%$ and $10 \%$. For the $4 \mathrm{E}$ material the strain rate sensitivity exponent $\mathrm{m}$ is $0.0115 \pm 0.01$ at $5 \%$, and $0.016 \pm 0.001$ at $10 \%$ strain, while for the $4 \mathrm{Bc}$ material, $\mathrm{m}$ is $0.0121 \pm 0.012$ at $5 \%$ and $0.012 \pm 0.006$ at $10 \%$ strain.
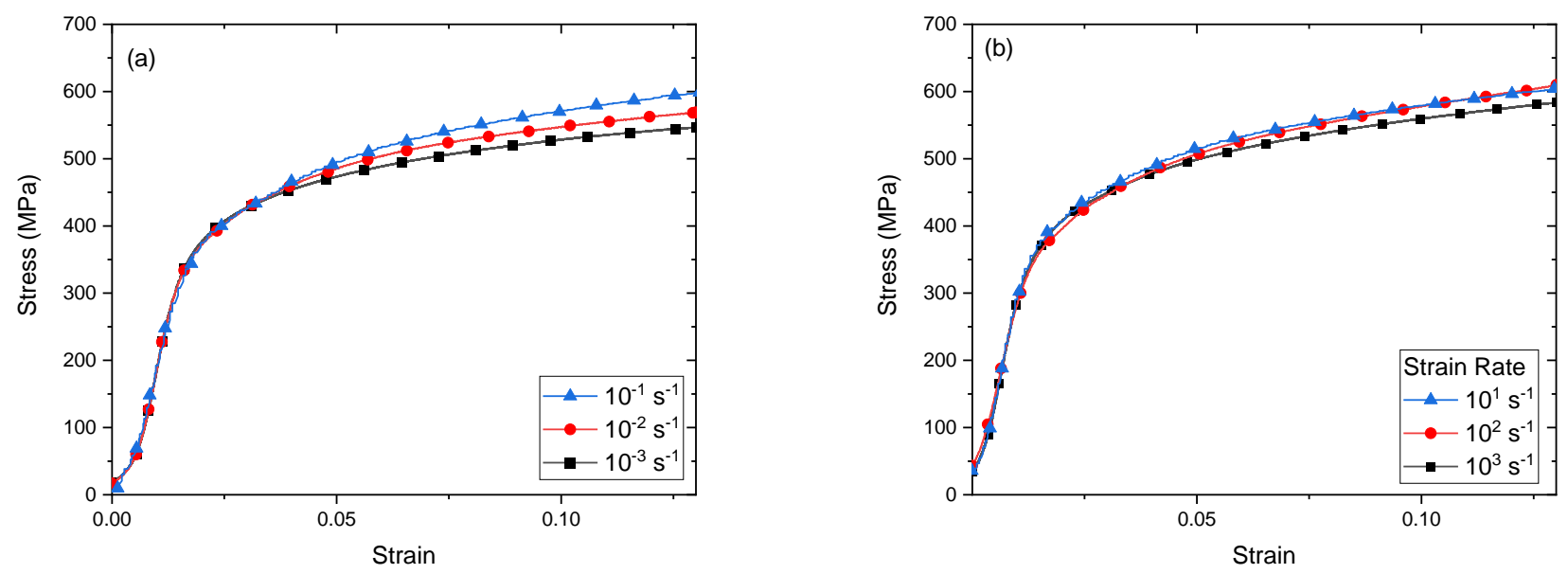

Figure 7. Experimental compression stress-strain curves of Cu50Ta consolidated at $300{ }^{\circ} \mathrm{C}$ tested at strain rates of $10^{-3}$, $10^{-2}, 10^{-1}, \mathrm{~s}^{-1}$ along the extrusion direction (ED). (a) By route $4 \mathrm{E}$, and (b) by route $4 \mathrm{Bc}$. 
Table 3. Summary of compression test results on $\mathrm{Cu}-\mathrm{Ta}$ composites processed by routes $4 \mathrm{E}$ and $4 \mathrm{Bc}$.

\begin{tabular}{|c|c|c|c|c|c|c|}
\hline Route & $\begin{array}{l}\text { Processing } \\
\text { Temperature }\end{array}$ & $\begin{array}{l}\text { Strain Rate } \\
\qquad\left(s^{-1}\right)\end{array}$ & $\begin{array}{l}\text { Testing } \\
\text { Direction }\end{array}$ & Yield Stress (MPa) & $\begin{array}{l}\text { Flow Stress at } \varepsilon=0.05 \\
(\mathrm{MPa})\end{array}$ & $\begin{array}{c}\text { Flow Stress at } \varepsilon=0.1 \\
(\mathrm{MPa})\end{array}$ \\
\hline $4 \mathrm{E}$ & ambient & $10^{-3}$ & ED & 427 & 595 & 560 \\
\hline- & - & $10^{-1}$ & ED & 360 & 502 & 574 \\
\hline- & - & $10^{-2}$ & ED & 342 & 495 & 551 \\
\hline $4 \mathrm{E}$ & $300^{\circ} \mathrm{C}$ & $10^{-3}$ & ED & $349 \pm 25$ & $476 \pm 4$ & $533 \pm 2$ \\
\hline- & - & $10^{-3}$ & FD & $387 \pm 1$ & $513 \pm 9$ & $563 \pm 4$ \\
\hline- & - & $10^{-3}$ & LD & $383 \pm 9$ & $518 \pm 13$ & $573 \pm 21$ \\
\hline- & - & $10^{-1}$ & ED & 371 & 516 & 578 \\
\hline- & - & $10^{-2}$ & ED & 346 & 507 & 577 \\
\hline $4 \mathrm{Bc}$ & $300^{\circ} \mathrm{C}$ & $10^{-3}$ & ED & $350 \pm 6$ & $488 \pm 12$ & $547 \pm 12$ \\
\hline- & - & $10^{-3}$ & FD & $379 \pm 4$ & $521 \pm 2$ & $579 \pm 1$ \\
\hline- & - & $10^{-3}$ & LD & $388 \pm 6$ & $504 \pm 6$ & $562 \pm 9$ \\
\hline
\end{tabular}

Values without \pm indicate results based on single test.

\section{Discussion and Conclusions}

We have shown that ECAE processing may be used to consolidate $\mathrm{Cu}$-Ta metal matrix composites from blended powders. ECAE routes that deform the material on multiple planes, such as routes $4 \mathrm{E}$ and $4 \mathrm{Bc}$, are most effective for bonding the constituent phases. Elevating the processing temperature from ambient to $300{ }^{\circ} \mathrm{C}$ produces a more malleable composite with reduced strength. Increasing the surface area between the $\mathrm{Cu}$ and $\mathrm{Ta}$ phases appears to increase yield strength while reducing plastic anisotropy and strain rate sensitivity.

Based on our findings, we conclude that the morphology of the composite constituent phases has a significant impact on consolidation and mechanical behavior of the final product. The trace length per phase area indicates strong mechanical interlocking of the $\mathrm{Cu}$ Ta interface. The amount of interlocking appears to be impacted not only by the total strain but also its path during deformation, as is the case when comparing material processing at ambient temperature. The $4 \mathrm{E}$, material being deformed along two separate planes due to the $90^{\circ}$ rotations between extrusions, has rough (longer) $\mathrm{Cu}$-Ta interfaces, mechanically interlocking the phases, as well as improved metallurgical bonds from the disruption of contaminated surfaces. In contrast, material 2A, which had the poorest mechanical behavior, may be well bonded along the single flow plane of extrusion. However, relatively poorer bonding along other planes may cause the constituent phases to buckle and separate from each other upon further deformation, resulting in reduced overall mechanical performance.

While processing routes $4 \mathrm{E}$ and $4 \mathrm{Bc}$ both restore the shape of the initial volume element, there are nevertheless some differences in their microstructure and mechanical behavior. In particular, route $4 \mathrm{Bc}$ results in greater interface trace length per unit section area, as shown in Table 2. This difference may account for improved bonding between the $\mathrm{Cu}$ and Ta phases, resulting in higher strength, more isotropic mechanical properties, and reduced sensitivity to strain rate.

\section{Future Work}

There are a number of avenues for continued improvement of consolidation by ECAE. Eliminating surface oxides by heating powders in a reducing atmosphere may enhance particle bonding. However, lack of surface oxides may accelerate ambient temperature bonding, thereby making it difficult to disperse the powders uniformly. To circumvent this possibility, methods for removing oxides after powder mixing should be explored.

Other possible routes for enhancing bonding and reducing porosity are pre-consolidation through ball milling, cold isotactic pressing (CIP), or increasing the number of ECAE passes. For instance, since route $4 \mathrm{Bc}$ proved effective, ECAE may be performed by route $8 \mathrm{Bc}$, the latter involving double the total number of passes. The additional ECAE passes need not be 
performed at the same temperature as the initial ones. For example, $4 \mathrm{Bc}$ may first be carried out at $300{ }^{\circ} \mathrm{C}$ followed by additional passes at room temperature.

The current work focused on $\mathrm{Cu}$-Ta composites with equal phase fractions by volume. Future work may also explore other $\mathrm{Cu}$ and Ta proportions. We anticipate that consolidation at high Ta fractions will pose challenges as Ta-Ta bonding may be weaker than the $\mathrm{Cu}-\mathrm{Cu}$ bonding at any processing temperature. Thus, maintaining a continuous $\mathrm{Cu}$ network may be beneficial.

Another avenue of future studies would be to explore combinations of $\mathrm{Cu}$ with other BCC metals, including $\mathrm{W}, \mathrm{Mo}, \mathrm{Nb}, \mathrm{W}, \mathrm{Cr}$, and $\mathrm{V}$. Since all of these BCC metals have vanishingly low solubility in $\mathrm{Cu}$, we anticipate their bonding behavior to be similar to that of $\mathrm{Cu}$-Ta. Enhanced bonding may be achievable in combinations of metals that are mutually soluble or that react to form intermetallic compounds. Examples include combinations BCC metals with HCP metals, such as Ti or Zr.

Supplementary Materials: The following are available online at https:/ /www.mdpi.com/article/10 .3390/met11071010/s1, Figure S1: Experimental compression stress-strain curves for Cu-Ta material processed at ambient temperature, Figure S2: Experimental compression stress-strain curves along the ED, FD, and $\mathrm{LD}$ for $\mathrm{Cu}$-Ta material processed by route $4 \mathrm{E}$ at $300^{\circ} \mathrm{C}$, Figure S3: Experimental compression stress-strain curves along the $\mathrm{ED}, \mathrm{FD}$, and $\mathrm{LD}$ for $\mathrm{Cu}$-Ta material processed by route $4 \mathrm{Bc}$ at $300^{\circ} \mathrm{C}$. Table S1: Summary of Young's modulus data measured from stress-strain curves.

Author Contributions: Conceptualization, Z.S.L., K.T.H. and M.J.D.; methodology, Z.S.L.; formal analysis, Z.S.L.; investigation, Z.S.L.; resources, Z.S.L.; data curation, Z.S.L.; writing-original draft preparation, Z.S.L.; writing—review \& editing, K.T.H. and M.J.D.; visualization, Z.S.L.; supervision, K.T.H.; project administration, Z.S.L.; funding acquisition, M.J.D. All authors have read and agreed to the published version of the manuscript.

Funding: This material is based upon work supported by the US Department of Energy, National Nuclear Security Administration under Award No. DE-NA0003857.

Informed Consent Statement: Not Applicable.

Data Availability Statement: The data presented in this study are available in Supplementary Materials https://www.mdpi.com/article/10.3390/met11070000/s1.

Acknowledgments: The authors thank R. E. Barber for support in EACE processing and B. Butler and J. Paramore for assistance with sample preparation and characterization. The raw/processed data required to reproduce these findings cannot be shared at this time due to technical or time limitations.

Conflicts of Interest: The authors declare no conflict of interest.

\section{References}

1. Patel, M.; Sahu, S.K.; Singh, M.K. Mechanical, Tribological and Corrosion Behaviour of Aluminium Alloys and Particulate Reinforced Aluminium or Aluminium Alloy Metal Matrix Composites-A Review. i-Manag. J. Mater. Sci. 2020, 8, 40.

2. Ray, A.K.; Venkateswarlu, K.; Chaudhury, S.; Das, S.; Kumar, B.R.; Pathak, L. Fabrication of TiN reinforced aluminium metal matrix composites through a powder metallurgical route. Mater. Sci. Eng. A 2002, 338, 160-165. [CrossRef]

3. Bose, A.; Sadangi, R.; German, R.M. A review on alloying in tungsten heavy alloys. Suppl. Proc. Mater. Process. Interfaces 2012, 1, 453-465.

4. Akhtar, F. An investigation on the solid state sintering of mechanically alloyed nano-structured 90W-Ni-Fe tungsten heavy alloy. Int. J. Refract. Met. Hard Mater. 2008, 26, 145-151. [CrossRef]

5. Scudino, S.; Liu, G.; Sakaliyska, M.; Surreddi, K.B.; Eckert, J. Powder metallurgy of Al-based metal matrix composites reinforced with $\beta$-Al3Mg2 intermetallic particles: Analysis and modeling of mechanical properties. Acta Mater. 2009, 57, 4529-4538. [CrossRef]

6. Varin, R. Intermetallic-reinforced light-metal matrix in-situ composites. Metall. Mater. Trans. A 2002, 33, 193-201. [CrossRef]

7. Lei, T.; Tang, W.; Cai, S.-H.; Feng, F.-F.; Li, N.-F. On the corrosion behaviour of newly developed biodegradable Mg-based metal matrix composites produced by in situ reaction. Corros. Sci. 2012, 54, 270-277. [CrossRef]

8. Sohag, M.A.Z.; Gupta, P.; Kondal, N.; Kumar, D.; Singh, N.; Jamwal, A. Effect of ceramic reinforcement on the microstructural, mechanical and tribological behavior of Al-Cu alloy metal matrix composite. Mater. Today Proc. 2020, 21, 1407-1411. [CrossRef]

9. Zou, H.; Wang, Y.C.; Li, S.K. Effect of composition on microstructure and dynamic mechanical properties of W-Ni-Cu alloys. Appl. Sci. Mater. Sci. Inf. Technol. Ind. 2014, 513-517, 121-124. [CrossRef] 
10. Gong, X.; Fan, J.L.; Ding, F.; Song, M.; Huang, B.Y. Effect of tungsten content on microstructure and quasi-static tensile fracture characteristics of rapidly hot-extruded W-Ni-Fe alloys. Int. J. Refract. Met. Hard Mater. 2012, 30, 71-77. [CrossRef]

11. Rieth, M.; Hoffmann, A. Influence of microstructure and notch fabrication on impact bending properties of tungsten materials. Int. J. Refract. Met. Hard Mater. 2010, 28, 679-686. [CrossRef]

12. Das, J.; Rao, G.A.; Pabi, S.K.; Sankaranarayana, M.; Nandy, T.K. Thermo-mechanical processing, microstructure and tensile properties of a tungsten heavy alloy. Mater. Sci. Eng. A 2014, 613, 48-59. [CrossRef]

13. Yu, Y.; Zhang, W.; Chen, Y.; Wang, E. Effect of swaging on microstructure and mechanical properties of liquid-phase sintered 93W-4.9(Ni, Co)-2.1Fe alloy. Int. J. Refract. Met. Hard Mater. 2014, 44, 103-108. [CrossRef]

14. German, R.M.; Bose, A.; Mani, S.S. Sintering time and atmosphere influences on the microstructure and mechanical-properties of tungsten heavy alloys. Metall. Trans. A Phys. Metall. Mater. Sci. 1992, 23, 211-219. [CrossRef]

15. Gong, X.; Fan, J.L.; Ding, F.; Song, M.; Huang, B.Y.; Tian, J.M. Microstructure and highly enhanced mechanical properties of fine-grained tungsten heavy alloy after one-pass rapid hot extrusion. Mater. Sci. Eng. A Struct. Mater. Prop. Microstruct. Process. 2011, 528, 3646-3652. [CrossRef]

16. Levin, Z.S.; Ted Hartwig, K. Hardness and microstructure of tungsten heavy alloy subjected to severe plastic deformation and post-processing heat treatment. Mater. Sci. Eng. A 2015, 635, 94-101. [CrossRef]

17. Barmouz, M.; Besharati Givi, M.K.; Seyfi, J. On the role of processing parameters in producing Cu/SiC metal matrix composites via friction stir processing: Investigating microstructure, microhardness, wear and tensile behavior. Mater. Charact. 2011, 62, 108-117. [CrossRef]

18. Balachandran, S.; Barber, R.E.; Huang, Y.; Miao, H.; Parrell, J.A.; Griffin, R.B.; Hartwig, K.T. Influences of Different ECAE Routes on Filament Deformation in Cu Clad Nb Composite Wires. IEEE Trans. Appl. Supercond. 2011, 21, 2584-2587. [CrossRef]

19. Kunčická, L.; Kocich, R.; Klečková, Z. Effects of Sintering Conditions on Structures and Properties of Sintered Tungsten Heavy Alloy. Materials 2020, 13, 2338. [CrossRef]

20. Gero, R.; Borukhin, L.; Pikus, I. Some structural effects of plastic deformation on tungsten heavy metal alloys. Mater. Sci. Eng. A Struct. Mater. Prop. Microstruct. Process. 2001, 302, 162-167. [CrossRef]

21. Suresh, S. Fundamentals of Metal-Matrix Composites; Elsevier: Amsterdam, The Netherlands, 2013.

22. Elliott, R. Eutectic Solidification Processing: Crystalline and Glassy Alloys; Elsevier: Amsterdam, The Netherlands, 2013.

23. Samal, C.; Parihar, J.y.; Chaira, D. The effect of milling and sintering techniques on mechanical properties of Cu-graphite metal matrix composite prepared by powder metallurgy route. J. Alloy. Compd. 2013, 569, 95-101. [CrossRef]

24. Balachandran, S.; Smathers, D.B.; Walsh, R.P.; Starch, W.L.; Lee, P.J. High-Strength Cu-Ta-W Composite. IEEE Trans. Appl. Supercond. 2019, 29, 1-4. [CrossRef]

25. Alizadeh, M.; Salahinejad, E. A comparative study on metal-matrix composites fabricated by conventional and cross accumulative roll-bonding processes. J. Alloy. Compd. 2015, 620, 180-184. [CrossRef]

26. Zeng, L.F.; Gao, R.; Fang, Q.F.; Wang, X.P.; Xie, Z.M.; Miao, S.; Hao, T.; Zhang, T. High strength and thermal stability of bulk $\mathrm{Cu} /$ Ta nanolamellar multilayers fabricated by cross accumulative roll bonding. Acta Mater. 2016, 110, 341-351. [CrossRef]

27. Mathaudhu, S.N.; Hartwig, K.T.; Karaman, I. Consolidation of blended powders by severe plastic deformation to form amorphous metal matrix composites. J. Non-Cryst. Solids 2007, 353, 185-193. [CrossRef]

28. Karaman, I.; Haouaoui, M.; Maier, H. Nanoparticle consolidation using equal channel angular extrusion at room temperature. J. Mater. Sci. 2007, 42, 1561-1576. [CrossRef]

29. Levin, Z.S.; Wang, X.; Kaynak, M.; Karaman, I.; Hartwig, K.T. Strength and ductility of powder consolidated ultrafine-grain tantalum. Int. J. Refract. Met. Hard Mater. 2019, 80, 73-84. [CrossRef]

30. Robertson, J.; Im, J.T.; Karaman, I.; Hartwig, K.T.; Anderson, I.E. Consolidation of amorphous copper based powder by equal channel angular extrusion. J. Non-Cryst. Solids 2003, 317, 144-151. [CrossRef]

31. Subramanian, P.R.; Laughlin, D.E. The Cu-Ta (Copper-Tantalum) system. Bull. Alloy Phase Diagr. 1989, 10, 652-655. [CrossRef]

32. Kaufman, L. Coupled thermochemical and phase diagram data for tantalum based binary alloys. Calphad 1991, 15, 243-259. [CrossRef]

33. Darling, K.; Tschopp, M.; Guduru, R.; Yin, W.; Wei, Q.; Kecskes, L. Microstructure and mechanical properties of bulk nanostructured $\mathrm{Cu}$-Ta alloys consolidated by equal channel angular extrusion. Acta Mater. 2014, 76, 168-185. [CrossRef]

34. Hornbuckle, B.C.; Rojhirunsakool, T.; Rajagopalan, M.; Alam, T.; Pun, G.P.P.; Banerjee, R.; Solanki, K.N.; Mishin, Y.; Kecskes, L.J.; Darling, K.A. Effect of Ta solute concentration on the microstructural evolution in immiscible Cu-Ta alloys. Jom 2015, 67, 2802-2809. [CrossRef]

35. Rajagopalan, M.; Darling, K.; Turnage, S.; Koju, R.K.; Hornbuckle, B.; Mishin, Y.; Solanki, K.N. Microstructural evolution in a nanocrystalline Cu-Ta alloy: A combined in-situ TEM and atomistic study. Mater. Des. 2017, 113, 178-185. [CrossRef]

36. Rajagopalan, M.; Darling, K.A.; Kale, C.; Turnage, S.A.; Koju, R.K.; Hornbuckle, B.C.; Mishin, Y.; Solanki, K.N. Nanotechnology enabled design of a structural material with extreme strength as well as thermal and electrical properties. Mater. Today 2019, 31, 10-20. [CrossRef]

37. Segal, V.M. Materials processing by simple shear. Mater. Sci. Eng. A 1995, 197, 157-164. [CrossRef]

38. Segal, V.M. Engineering and commercialization of equal channel angular extrusion (ECAE). Mater. Sci. Eng. A 2004, 386, 269-276. [CrossRef]

39. Levin, Z.S.; Hartwig, K.T. Strong ductile bulk tungsten. Mater. Sci. Eng. A 2017, 707, 602-611. [CrossRef] 
40. Schindelin, J.; Arganda-Carreras, I.; Frise, E.; Kaynig, V.; Longair, M.; Pietzsch, T.; Preibisch, S.; Rueden, C.; Saalfeld, S.; Schmid, B.; et al. Fiji: An open-source platform for biological-image analysis. Nat. Methods 2012, 9, 676-682. [CrossRef] [PubMed]

41. Springs, J.; Kao, Y.; Srivastava, A.; Levin, Z.; Barber, R.; Hartwig, K. Strength and electrical resistivity of heavily worked copper. IOP Conf. Ser. Mater. Sci. Eng. 2017, 279, 012003. [CrossRef] 